\section{Intermediate expansions of a X25/frataxin gene GAA repeat and Type II diabetes: assessment using parent-offspring trios}

Dear Sir,

Homozygous expansions greater than 66 repeat lengths of a GAA repeat in the first intron of the $X 25 /$ frataxin gene have been linked with the development of Friedreich's ataxia (FRDA) [1]. Abnormal glucose tolerance is present in $30 \%$ of FRDA patients, with about $10 \%$ having overt diabetes [2]. Intermediate GAA repeat expansions (10-36 repeats) do not lead to the FRDA phenotype but a recent case control study reported an increased prevalence in Type II (non-insulin-dependent) diabetes mellitus [3]. This has not been replicated in subsequent studies [4-6], although non-diabetic carriers of the intermediate expansion were found to have abnormal insulin secretion [6].

These studies exploring the importance of intermediate expansions in Type II diabetes have all been case control studies, which are susceptible to the generation of spurious results due to population stratification. A family-based association method using parent-offspring trios can overcome this problem as it detects only those associations due to linkage [7]. This approach also allows parent-of-origin effects to be examined, which case control studies cannot detect [7]. This is particularly relevant to FRDA as intergeneration expansion of the GAA repeat has only been reported with maternally transmitted alleles [8], and larger expansions are associated with a more severe clinical phenotype [2].

We have therefore examined the importance of intermediate GAA expansions in Type II diabetes using the British Diabetic Association-Warren 2 Trio collection which comprises parent-offspring trios ascertained through Type II diabetic probands with both parents alive [7]. After exclusion of known subtypes of diabetes (mitochondrial-related diabetes, maturity-onset diabetes of the young, and late-onset autoimmune diabetes) and families with inconsistent family relationships, 155 parent-offspring trios were available for study. Identification of the intermediate expansion was carried out using a PCR-based technique [3].

Screening of the diabetic offspring showed that $37(24 \%)$ were carriers of intermediate expansions. Table 1 summarises the transmission data and shows that 75 parents were heterozygous carriers of which $40(53 \%)$ transmitted the intermediate expansion to their diabetic offspring ( $p=0.64$, assuming

Corresponding author: Dr. M. Walker, Department of Medicine, The Medical School, Framlington Place, Newcastle upon Tyne, NE2 4HH, UK
Table 1. Transmission of intermediate expansions from heterozygous parents to Type II diabetic offspring. A binomial test compared observed against an expected transmission of $50 \%$

\begin{tabular}{llll}
\hline & Transmission & Non-transmission & $p$ value \\
\hline Parental heterozygotes & 40 & 35 & 0.64 \\
Maternal & 16 & 14 & 0.86 \\
Paternal & 23 & 20 & 0.76 \\
\hline
\end{tabular}

expected $50 \%$ transmission). Considering parent-of-origin effects, one parent-offspring trio had to be excluded because parent of origin could not be assigned as all were heterozygous carriers of the same sized expansion. As shown in Table 1, 16 out of $30(53 \%)$ maternal and 23 of $43(54 \%)$ paternal heterozygous carriers transmitted the intermediate expansion to their diabetic offspring ( $p=0.86$ and 0.76 , respectively, assuming expected $50 \%$ transmission).

Thus, using a family-based association test we have found no evidence of preferential transmission of intermediate expansions of the $X 25$ /frataxin gene in Type II diabetic trio families. Although maternal transmission of large expansions in FRDA influence phenotypic expression [8], there was no evidence of preferential maternal or paternal transmission of intermediate expansions in Type II diabetes. Therefore, we have found no evidence to implicate intermediate expansions of the frataxin gene in the aetiology of Type II diabetes.

S. Lynn, A. T. Hattersley, M. I. McCarthy, T. M. Frayling, D. M. Turnbull, M. Walker

\section{References}

1. Campuzano V, Montermini L, Molto MD et al. (1996) Friedreich's ataxia: autosomal recessive disease caused by an intronic GAA triplet repeat expansion. Science 271: 1423-1427

2. Durr A, Cosse M, Agid Y et al. (1996) Clinical and genetic abnormalities in patients with Friedreich's ataxia. N Eng J Med 335: 1169-1175

3. Ristow M, Giannakidou E, Hebinck J et al. (1998) An association between NIDDM and a GAA trinucleotide repeat polymorphism in the X25/frataxin (Friedreich's ataxia) gene. Diabetes 47: 851-854

4. Dupont S, Dubois D, Vionnet N et al. (1998) No association between the Friedreich's ataxia gene and NIDDM in the French population. Diabetes 47: 1654-1656

5. Dalgaard LT, Hansen T, Urhammer SA, Clausen JO, Eiberg H, Pedersen O (1999) Intermediate expansions of a GAA 
repeat in the frataxin gene are not associated with type 2 diabetes or altered glucose induced $\beta$-cell finction in Danish caucasians. Diabetes 48: 914-917

6. 't Hart LM, Ruige JB, Dekker JM, Stehouwer CDA, Maasen JA, Heine RJ (1999) Altered $\beta$-cell characteristics in impaired glucose tolerant carriers of a GAA trinucleotide repeat polymorphism in the frataxin gene. Diabetes 48: 924-926
7. Huxtable SJ, Saker PJ, Haddad L et al. Analysis of parentoffspring trios provides evidence for linkage and association between the insulin gene and type 2 diabetes mediated exclusively through paternally-transmitted class III VNTR alleles. Diabetes (in press)

8. Pianese L, Cavalcanti F, de Michele G et al. (1997) The effect of parental gender on the GAA dynamic mutation in the FRDA gene. Am J Hum Genet 60: 460-463

\section{Effects of metformin on androgens and insulin concentrations in type A insulin resistance syndrome}

\section{Dear Sir,}

Insulin receptor gene mutations have been described in type A insulin resistance syndrome, characterized by hyperinsulinaemia, acanthosis nigricans and hyperandrogenism [1].

Non-obese women with polycystic ovary syndrome, a form of functional ovarian hyperandrogenism have an intrinsic form of insulin resistance that is unique to the disorder [2]. Treatment with insulin-sensitizing agents, such as metformin, has been shown to reduce insulin resistance, to statistically significantly decrease androgen concentrations and to initiate menstrual cyclicity in these patients [3]. These effects are consistent with the hypothesis that hyperinsulinaemia and insulin resistance have an aetiological role in hyperandrogenism through stimulation of ovarian and adrenal steroidogenesis.

We report the results of a 10-month treatment with metformin ( $850 \mathrm{mg}$ twice daily) in a lean (body mass index, 20 $\mathrm{Kg} / \mathrm{m}^{2}$ ), girl aged 13 years 6 months with severe hirsutism, acne, clitoral hypertrophy, acanthosis nigricans and primary amenorrhea. Basal hormonal assessment showed high total serum testosterone, 17-hydroxyprogesterone, androstenedione, immunoreactive insulin concentrations and decreased sex hormone-binding globulin concentrations. A tumoral origin of the hyperandrogenism was ruled out by appropriate imaging studies. Short-term leuprolide acetate stimulation (Procrin, Abbott, Madrid, Spain, $500 \mu \mathrm{g}$, s.c), elicited an increase in ovarian 17-hydroxyprogesterone concentrations (30.6 nmol/l) suggestive of functional ovarian hyperandrogenism. A standard oral glucose tolerance test produced insulin peaks of more than $3587 \mathrm{pmol} / \mathrm{l}$ at all time points, with normal glucose tolerance.
Molecular analysis of the insulin receptor gene showed a heterozygous novel missense mutation in exon 17 of the insulin receptor gene (Ala1028 $\rightarrow$ Val) abolishing autophosphorilation of the insulin receptor $\beta$-subunit.

Basal androgens and fasting insulin concentrations decreased significantly during treatment whereas sex hormonebinding globulin concentrations increased (Table 1). Breast development progressed and menarche occurred in the fifth month of therapy. No side-effects were documented.

Metformin is a biguanide hypoglycaemic agent that increases peripheral utilization of glucose, acting in the early steps of insulin signal transduction through potentiating phosphatidylinositol-3' kinase pathway of insulin receptors [4] and decreasing ovarian and adrenal cytochrome P450c17 activity [3]. Prolonged treatment with metformin has been proved to be safe in Type II (non-insulin-dependent) diabetes mellitus and in a pregnant hyperandrogenic woman [5]. Metformin, troglitazone (a thiazolidinedione derivative) and the D-chiroinositol-containing phosphoglycan mediator of the action of insulin, reduce hyperinsulinism and hyperandrogenism in women with functional ovarian hyperandrogenism. The new agent L-783,281, recently identified as a non-peptidyl fungal metabolite, seems to act by stimulating tyrosine kinase activity of insulin receptors [7]. Although this drug might have beneficial effects in insulin resistance states due to insulin receptor mutations in the $\alpha$-subunit, it might be ineffective in tyrosin kinase domain mutations of the insulin receptor in which this activity is abolished.

Our results show the usefulness and safety of metformin therapy in an adolescent with type A insulin resistance syndrome associated with severe hyperandrogenism.

Yours sincerely, S. Rique, L. Ibáñez, M. V. Marcos, A. Carrascosa, N. Potau

Table 1. Clinical data, androgen and sex hormone-binding globulin concentrations and fasting glucose and insulin concentrations before and after 5 and 10 months of metformin treatment ( $850 \mathrm{mg}$ twice daily)

\begin{tabular}{llllllllll}
\hline & $\begin{array}{l}\text { Tanner } \\
\text { breast stage }\end{array}$ & $\begin{array}{l}\text { hirsutism } \\
\text { score }\end{array}$ & $\begin{array}{l}\text { TT } \\
\text { nmol/l }\end{array}$ & $\begin{array}{l}\text { SHBG } \\
\text { nmol/l }\end{array}$ & FAI & $\begin{array}{l}\text { 17-OHP } \\
\text { mmol/l }\end{array}$ & $\begin{array}{l}\Delta^{4} \text {-A } \\
\text { nmol/1 }\end{array}$ & $\begin{array}{l}\text { glucose } \\
\text { mmol/l }\end{array}$ & $\begin{array}{l}\text { insulin } \\
\text { pmol/1 }\end{array}$ \\
\hline Baseline & II & 20 & 8.3 & 31.2 & 13.5 & 10.5 & 12.0 & 4.9 & 1127.9 \\
5 months & III & 17 & 2.1 & 48.6 & 6.4 & 1.9 & 10.9 & 4.2 & 581.8 \\
10 months & V & 10 & 1.7 & 48.6 & 4.3 & 1.9 & 10.8 & 4.3
\end{tabular}

${ }^{\mathrm{a}}$ Ferriman and Gallwey score (normal $\leq 8$ ); TT, total testosterone; SHBG, sex hormone-binding globulin; FAI, free androgen index (equivalent to free testosterone; normal $\leq 5$ ); 17-OHP, 17-hydroxyprogesterone; $\Delta^{4}$-A, androstenedione.
Normal values for age-matched control girls (mean $\pm \mathrm{SD}$; $n=40)$ : TT, $0.7 \pm 0.3 \mathrm{nmol} / \mathrm{l} ; \mathrm{SHBG}, 59.0 \pm 6.9 \mathrm{nmol} / \mathrm{l}$; $17-$ OHP, $\quad 1.8 \pm 0.01 \mathrm{nmol} / \mathrm{l} ; \quad \Delta^{4}-\mathrm{A}, \quad 4.4 \pm 1.7 \mathrm{nmol} / \mathrm{l} ; \quad$ insulin, 35.9-107.6 pmol/1

Corresponding author: N. Potau MD, Hormonal Laboratory, Hospital Materno-Infantil Vall d'Hebron, Passeig Vall d'Hebron 119-129, E-08035 Barcelona, Spain 